\title{
Statement of Concern
}

Re: Bolourani S, Tayebi MA, Diao L, Wang P, Patel V, Manetta F, Lee PC. Using machine learning to predict early readmission following esophagectomy. J Thorac Cardiovasc Surg. May 29, 2020 [Epub ahead of print].

In the above-mentioned article, the authors discovered an erroneous line of program code in the experimentation of the 3 methods presented in Figure 4. The editors will review the implications of the error. 